\title{
SENTIMENTS IN INDUSTRY IN MAY 2016: NOT GOOD ENOUGH BUT NOT PARTICULARLY BAD ${ }^{1}$
}

\author{
S.Tsukhlo
}

Positive dynamics of demand and output of industrial products amid minimal surplus of stocks of finished products combines in May 2016 with growth of uncertainty in future demand. There is no confidence regarding the investment plans and there is no pessimism regarding servicing of loans.

\section{Demand, stocks and output}

Demand dynamics of March-May 2016 demonstrate unexpectedly stable for those months initial changes in sales of industrial products. Even the month of May, which missed a few working days, failed to reduce the amount of demand and retained the difference in responses "growth" and "decrease" at the level of March-April. As a result, seasonal adjustment has placed the May demand change at the highest value observed since February 2014.

Definitely positive dynamics of demand posted over recent months has increased satisfaction with its volumes since the turn of the year by 15 p.p. As a result, at present $54 \%$ of Russian enterprises consider sales of their products as normal.

However, forecasts of demand, which were steadily becoming more optimistic according to seasonal and calendar adjusted data unexpectedly crashed in May by 8 p.p. It seems that industry is unsure in retaining such positive demand dynamics, which it faced during recent months. Pessimism expressed by officials and experts does not contribute to the growth of optimism of enterprises.

Estimates of stocks of finished products confirm the conclusion about a positive dynamics of demand posted during recent months. "Excess" of stocks posted in March 2016 (has fallen sharply (by 6 p.p.) (+2 -+3 p.p.). In May, balance of estimates was taking shape both amid contraction of responses "above normal" and responses "below normal." As a result, the share of these responses (10 and 7\%, respectively) reached all-time high over the entire period (1992-2016) of monitoring estimates (not volumes) of stocks in Russian industry. Estimates of stocks as "normal" still remain stable and are in the range of $70-72 \%$,

Decrease of estimates of stocks ("above normal", "normal," and below normal") was due to the growth of responses "no answer," which reflects industry's lack of understanding what physical volume of stocks is proper for the current situation. In May 2016, eleven percent of enterprises renounced definitive estimates of their stocks, which exceeded the share of responses "above normal" or "below normal." Although in January 2016, merely 5\% of enterprises renounced definitive estimates of their stocks.

Similar high level of renunciation of definitive estimates of their stocks of finished products was registered by business surveys conducted by the IEP in 2000-2002. Then, the enterprises finally believed in stability of industrial

1 This paper was originally published in Online Monitoring of Russia's Economic Outlook No.9(27). 
growth following 1998 default were in transition from the practice of rigid minimization of their stocks to their reasonable control and later - to estimate stocks as "normal." This transition was accompanied by a logical growth of uncertainty in estimates of stocks of finished products. Since mid-2003 through mid-2015 uncertainty in estimates of stocks of finished products did not exceed $5 \%$ on average per quarter. However, by late 2015 and at the beginning of 2016, this indicator went up to $7 \%$ and by the average level of the first two months Q2 2016 constituted already 10\%.

Actually, output dynamics registered in May also demonstrates positive: seasonal adjusted balance of changes (growth rate) of industrial production reached maximum values observed since October 2014.

However, output plans of Russian industry, which overcame in MarchApril the worst for the current crisis expectations of January-February 2016 stopped gathering confidence and contracted in May by 3 p.p. Enterprises, probably, are not sure in retaining positive trends. This is logical in the wake of sharply negative correction of May demand forecasts.

\section{Capacity adequacy}

In the wake of constantly delayed recovery growth, the industry is reviewing their estimates of capacity adequacy and supply of workers. What is more - towards their improved sufficiency.

Capacity shortage due to expected by industry changes in demand on output product dropped to 5\% in Q2 2016. This is nearly the minimal level of equipment shortage for the whole period of monitoring since 1993. Lower capacity shortage (3\%) was registered by the IEP business surveys on the eve of the default, in April 2009, and in January 2013. Staff shortage in industry is big but also decreased compared to the turn of 2016. The latest value of the indicator is 9\%, which is minimal since January 2010.

Maximum capacity shortage at the sectoral level hits $10 \%$ (registered by $10 \%$ of enterprises) and has been registered in the chemical, timber, and construction industries. However, this shortage (less timber) is offset by a considerable overhang of excessive capacities: $30 \%$ in the chemical industry and $48 \%$ in the construction industry. Shortage of capacity in machine building and light industry registered in Q2 2016 constitutes 6\%, but is offset by their surplus in $28 \%$ and $56 \%$, respectively. Annual average data on capacities shortage in sectors of industry (for the first two quarters in 2016) reflect rather modest scale of this phenomenon, which furthermore in all cases (minus timer industry) are offset by a considerable overhang of surplus capacities.

\section{Prices of enterprises}

In May, Russian industry froze growth of its prices: the balance of their actual changes (growth rate) decreased from +9 p.p. in April to +1 p.p. in May and turned out to be the minimal value of this indicator in 2016. Nevertheless, in 2015 , industry managed to cut balance to -2 p.p. However, exceptionally moderate May price growth hardly continues in the coming months. Balance of price forecasts went up in May by 9 p.p. following hitting in April the minimal for $2016+7$ p.p.

Accuracy of forecasts precision (plans) of three major indicators (demand, output and prices) demonstrate that Russian industrial enterprises were more precise in forecasting changes of their prices. Accuracy of price fore- 
casts averaged in some years $73-74 \%$ and in certain months $-80 \%$. The worst $(60 \%)$ forecast performance was obtained in following the default years 1999-2002. Accuracy of forecasts in the current 2016 along four months averages $69 \%$. The April forecast came true for $80 \%$ of enterprises in May, which is the highest value of this indicator.

Analysis of mistakes in price forecasts (their share complements the share of accurate forecasts to $100 \%$ ) demonstrates that Russian industry was persistently wrong by overestimating its projections. As a result, the balance of mistakes (overestimated minus understated) apart from rare and insignificant exceptions turned out to be positive. Especially significant and prolonged (despite blunders) were mistakes of 1999-2002. Then the share of mistakenly overstated forecasts hit record $30 \%$ against $7-9 \%$ of mistakenly understated forecasts.

Prior to crisis 2008-2009, industry also started to overstate oftener its price forecasts, although commenced demand contraction forced businesses to conduct a more accurate actual pricing policy. In June-October 2008, the balance of mistakes committed in price forecasts was in the range of $+14-+17$ p.p. with forecasts precision at $70 \%$.

Quite another pricing policy Russian industry was conducting prior to crisis 2014-2016. From March 2014 (outbreak of geopolitical tension) precision of price forecasts of businesses were steadily growing and hit in August 2014 a record high of $81 \%$. At the same time, the balance of mistakes increased to 6 p.p. "at best" and from August 2014 became zero, i.e. mistakes in forecasts interbalanced one another. When Russian countersanctions triggered the inflationary spiral and closer to disastrous December 2014, businesses' price forecasts commenced reducing their precision: by the end of the year, the indicator shed 17 p.p. and returned to the minimum levels of 2005-2014. However, the balance of mistakes in price forecasts remained around zero through August 2015.

\section{Investment plans and problems of industry}

In May, businesses' investment plans consolidated at the level of a moderate pessimism of January-February 2016 following demonstration of a crisis maximum in March. Thus, Russian industry still cannot make up its mind to the positive investment dynamics. So far, it has managed to reduce investment pessimism from -36 p.p. posted in February 2015 to -2 p.p. posted in March 2016. However in April 2016, they failed to retain the obtained result.

"Shortage of their own financial resources" has been considered up till now as a number one (most widespread) obstacle to investment in industrial production. In 2016, the magnitude of this indicator fell to its all-time low over the entire observation period (1996-2016). Currently, only half of businesses consider this factor as a hindrance (worst result - $91 \%$ was registered in 1998). High prices of equipment and high interest rates on bank loans come with $44 \%$ in the rating list of obstacles to investment. However, this year interest rates on bank loans were mentioned less by 4 p.p., then high prices on equipment were mentioned oftener by 2 p.p. against 2015. Thus, in 2016, not a single restriction of the second level was subject to significant change of its impact on the investment activity of Russian industry.

Other three factors have shown the highest growth (by 7 p.p.) of downward pressure in 2016 compared to 2015. The factor of uncertainty in a speedy economic revival in the near future has moved up to $32 \%$, although 
in 2013 such uncertainty was in the way for investment activity of solely $21 \%$ of businesses and in 2014 and 2015, it went up by merely 2 p.p. per annum.

Thus, protracted character of the slow rolling crisis with dim outlook for its termination has been exerting ever-increasing downward pressure on the investment activity of Russian industry. In 2016, 26\% of businesses experienced difficulties with obtaining long-term loans, meanwhile prior to crisis 2014-2016, merely $10 \%$ of enterprises complained about this factor. It turns out that over two crisis years Russian banks have significantly complicated extension of investment loans to industrial enterprises amid reducing interest rates. Features of the national investment climate negatively impact on the investment plans of 15\% of businesses, meanwhile in 2013-2015 barely $6-9 \%$ of respondents complained about it.

\section{Lending to Russian industry}

The May estimates have reflected retention of the same level of availability of loans for Russian industry, which since January 2016 is estimated by business on average at $50 \%$ with fluctuations in the range of $49-51 \%$. Thus in 2016, stability has been achieved on one more economic indicator. Herewith, the minimum corporate interest rate decreased over 5 months of 2016 from $16.4 \%$ to $15.7 \%$ per annum in rubles. Overall reduction of this indicator came to 0.9 p.p. since august 2015 (i.e. from the date the Bank of Russia held its key rate at $11 \%)$.

Industry's estimated ability to service loans remains at high level. In Q2 $2016,85 \%$ of respondent enterprises, which use loans, cited it. This indicator hit the maximum high (88\%) in August 2014.

At the same time, in Q2 2016, the balance of borrowing plans has undergone a sharp reduction (by 11 p.p.) compared to Q1 2016. In comparison with Q4 2015, the reduction has already constituted 17 p.p. In consequence, the maximum level of the borrowing plans (+24 p.p.) over two quarters has given way to the minimum (+7 p.p.) during five-year monitoring of the indicator. Russian industry less and less needs bank lending for such industrial growth. 